\title{
Structural Characterization and Cytolytic Activity of a Potent Antimicrobial Motif in Longicin, a Defensin-Like Peptide in the Tick Haemaphysalis longicornis
}

\author{
Md. Morshedur RAHMAN ${ }^{1)}$, Naotoshi TSUJI'), Damdinsuren BOLDBAATAR ${ }^{1)}$, Banzragch BATTUR ${ }^{1)}$, Min LIAO $^{1)}$, \\ Rika UMEMIYA-SHIRAFUJI ${ }^{1)}$, Myungjo YOU ${ }^{3)}$, Tetsuya TANAKA ${ }^{1)}$ and Kozo FUJISAKI ${ }^{1) *}$ \\ ${ }^{1)}$ Department of Frontier Veterinary Medicine, Kagoshima University, Korimoto, Kagoshima 890-0065, 2)National Institute of Animal \\ Health, National Agricultural Research Organization, Ibaraki 305-0856, Japan and ${ }^{3}$ Department of Veterinary Parasitology, College of \\ Veterinary Medicine, Chonbuk National University, Duckjin-dong, Jeonju 561-756, Korea
}

(Received 14 June 2009/Accepted 15 September 2009/Published online in J-STAGE 25 November 2009)

\begin{abstract}
Longicin, a defensin-like peptide, was recently identified in the hard tick Haemaphysalis longicornis. Longicin and one of its synthetic partial analogs (P4) displayed antimicrobial/fungicidal/parasiticidal activity. In the present study, we compared longicinderived synthetic analogs in order to characterize the antimicrobial motif (P4) by analyzing some structural features using various bioinformatic tools and/or CD spectroscopy. According to the chemicophysical characteristics, P4 is suggested to be a cationic peptide with hydrophobic and amphipathic character. The predicted secondary structure indicated the existence of a $\beta$-sheet, which was also observed in the modeled tertiary structure. CD spectroscopic results also showed the existence of a $\beta$-sheet and transition to a helical conformation in the presence of membrane-mimicking conditions. These structural observations on P4 suggested that the antimicrobial activity could be due to the $\beta$-sheet as well as the $\alpha$-helix. In addition, a sequence homology search showed that molecules identified in other ticks and organisms also have the $\mathrm{P} 4$ analogous domain at their C-terminal, which indicates $\mathrm{P} 4$ as a conserved domain. The peptide $\mathrm{P} 4$ also showed low cytolytic activity. Based on the present result and previously reported studies, the peptide P4 could be suggested as a novel antimicrobial domain indicating future therapeutic agent against bacteria.

KEY WORDS: antimicrobial peptides, longicin, P4, structure.
\end{abstract}

Antimicrobial peptides represent an essential alternative first line of defense. Searching for more potent and effective antibiotics to combat pathogens having resistance to conventionally used antibiotics is of great interest [32]. Naturally occurring molecules involved with the innate immune system in disease-bearing vectors, such as mosquito and the tick, could be the target due to their well developed and diverse protective immune system. Disease-transmitting arthropod vectors have an extensive spectrum of innate immunity mechanisms comprising different types of useful and important molecules $[2,5,6,8,11]$. Therefore, these molecules could be the effective agents against pathogens. Small antimicrobial peptides, such as cecropin, defensin, maganin, and melittin, have been reported as the most potent naturally occurring antibiotics [20].

Ticks encounter various microbes through sucking blood from an infected host or a microbe-friendly environment, and they play as important vectors of a wide variety of disease-causing bacteria, viruses, protozoa, and other pathogenic microorganisms. Defensin-like proteins in several ticks have already been reported $[3,7,13,17,19,23,27$, 40]. We also recently explored the expression of a defensinlike peptide, longicin, from the midgut epithelium of the hard tick Haemaphysalis longicornis [33]. Longicin consists of 74 amino acids, of which 22 residues were detected

\footnotetext{
* Correspondence to: Fujisaki, K., Department of Frontier Veterinary Medicine, Kagoshima University, Korimoto, Kagoshima 890-0065, Japan.

e-mail: tick@ms.kagoshima-u.ac.jp
}

as a signal peptide. We also evaluated the antimicrobial activity of longicin and four of its synthetic analogs, namely, P1 (residues 23-37), P2 (33-45), P3 (42-57), and P4 (53-73). Longicin and one of its synthetic analog (P4) displayed antimicrobial/fungicidal/parasiticidal activity and they were, therefore, proposed to be therapeutic agents against tick-borne pathogens. Interestingly, three other synthetic analogs of longicin (P1, P2, and P3) were inactive against microorganisms [33]. Thus, the peptide $\mathrm{P} 4$ is indicated as a potent antimicrobial motif in longicin. These findings led us to analyze the structural differences among the synthetic analogs derived from longicin.

The structural characterization of antimicrobial peptides is very important to understand the peptide activity. So far, hundreds of antimicrobial peptides have been isolated from various organisms, and their great diversity in the primary structure results in the large difference in their antibacterial mechanisms [35]. In addition, harmful side effects, such as the lysis of red blood cells [1, 16, 29] or cytotoxicity towards mammalian host cells $[9,37,38]$, which are commonly associated with antimicrobial peptides as potential therapeutic agents, should also be elucidated. In this study, we analyzed some structural features of longicin and longicin-derived synthetic peptides in relation with their antimicrobial potential using various bioinformatic tools and/or CD spectroscopy. We also determined the cytolytic activity of P4 peptide for evaluating the safety/toxicity of the peptide. 
Table 1. Predicted chemicophysical properties of longicin and its partial peptides

\begin{tabular}{|c|c|c|c|c|c|c|c|c|c|}
\hline \multirow{3}{*}{ Peptides $^{\text {a) }}$} & \multirow{3}{*}{ Sequence ${ }^{b)}$} & \multicolumn{8}{|c|}{ Predicted chemicophysical characteristics } \\
\hline & & \multirow{2}{*}{ Length } & \multirow{2}{*}{$\begin{array}{l}\text { Molecular } \\
\text { mass }(\mathrm{Da})^{\mathrm{c})}\end{array}$} & \multicolumn{2}{|c|}{ Mean amphipathicity ${ }^{\mathrm{d})}$} & \multirow{2}{*}{$\begin{array}{l}\text { GRAVY } \\
\text { index }^{c}\end{array}$} & \multirow{2}{*}{$\begin{array}{l}\text { Aliphatic } \\
\text { index }^{\text {c) }}\end{array}$} & \multirow{2}{*}{$\mathrm{pI}^{\mathrm{c})}$} & \multirow{2}{*}{$\begin{array}{c}\text { Net } \\
\text { charge }^{\text {c) }}\end{array}$} \\
\hline & & & & $\alpha$-helix & $\beta$-sheet & & & & \\
\hline Longicin & QDDESDVPHVRVRRGFGCPLNQGACHNHCRSIGRRGGYCAGIIKQTCTCCYP & КK 52 & 5820.6 & 0.76 & 0.54 & -0.783 & 50.58 & 9.15 & +5 \\
\hline P-1 & QDDESDVPHVRVRRG & 15 & 1764.8 & 0.39 & 0.53 & -1.627 & 58.00 & 5.43 & -1 \\
\hline $\mathrm{P}-2$ & RVRRGFGCPLNQG & 13 & 1459.6 & 1.16 & 1.55 & -0.769 & 55.78 & 11.7 & +3 \\
\hline P-3 & LNQGACHNHECRSIGRR & 16 & 1822.0 & 0.93 & 0.28 & -1.056 & 55.00 & 10.41 & +3 \\
\hline P-4 & 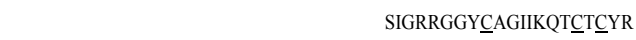 & 21 & 2306.7 & 1.11 & 0.25 & -0.214 & 60.48 & 9.50 & +4 \\
\hline
\end{tabular}

a) Longicin and one of its analog, P4, were reported to be active against bacteria, parasites, and fungi, as described by Tsuji et al. [33].

b) The longicin sequence represents only the putative mature protein; sequences were taken from Tsuji et al. [33]; the cysteine residues are underlined.

c) Predicted by ProtParam, a primary structure analysis tool located on the ExPASy server.

d) Calculated using the software WHAT [39] assuming that peptides adopt either an $\alpha$-helical ( $100^{\circ}$ angle $)$ or a $\beta$-sheet $\left(180^{\circ}\right.$ angle $)$ conformation.

\section{MATERIALS AND METHODS}

Synthetic peptides: The synthetic peptides used in this study were prepared by Sigma Aldrich, Japan with a purity of $>95 \%$. The sequences and chemicophysical characteristics of them are listed in Table 1.

Structure prediction: Various bioinformatic tools and software were used to predict the peptides' structure. The tool ProtParam (http://br.expasy.org/tools/protparam.html), located on the ExPASy Server, was used to analyze the peptides' chemicophysical characteristics. The mean amphipathicity was calculated using the program WHAT [39]. The software Arguslab 4.0.1 was used to generate a brokenheaven pdb file, which was then loaded on the software CCP4MG [25] to compute the electrostatic potential. The Hierarchical Neural Network (HNN) (http://npsapbil.ibcp.fr/cgi-bin/npsa_automat.pl?page=npsa_nn.html), also located on the ExPASy Server, was used to predict the secondary structure of peptides. The disulphide bond was predicted by DIpro (http://scratch.proteomics.ics.uci.edu/). The modeled tertiary structure was generated through the Swiss-Model Protein Modeling Server (http://swissmodel.expasy.org/SWISS-MODEL.html). A helical wheel was projected using the software Antheprot 2000 V 6.0. A sequence similarity search against protein databases was performed using the FASTA and SSEARCH programs (http://www.ebi.ac.uk/Tools/fasta33/index.html).

Circular dichroism (CD) spectroscopy: To determine the secondary structure of the peptides P1 (as negative control) and P4, CD spectroscopy was performed with a Jasco J-820 spectropolarimeter (JASCO, Tokyo, Japan) using a $1-\mathrm{cm}$ path length cell over the $190-250 \mathrm{~nm}$ range. The spectra were acquired at $25^{\circ} \mathrm{C}$ every $0.5 \mathrm{~nm}$ with a $1 \mathrm{~s}$ averaging time per point and a $1 \mathrm{~nm}$ band pass. Four scans with a scan speed of $20 \mathrm{~nm} / \mathrm{min}$ were also averaged for each peptide. Peptides were dissolved in Mili-Q water containing 50\% trifluoroethanol (TFE) or $25 \mathrm{mM}$ sodium dodecyl sulfate (SDS) or in Mili-Q water only at a concentration of $0.2 \mathrm{mg} /$ $\mathrm{m} l$. CD spectral results were expressed as the mean residue ellipticity. The contents of four types of the secondary structural elements, namely, $\alpha$-helix, $\beta$-sheet, $\beta$-turns, and random coils, were determined.

Hemolysis assay: The peptide $\mathrm{P} 4$ was challenged against the erythrocytes of different species, and the hemolytic activity was determined as described previously [31] with some modifications. Briefly, fresh anticoagulated blood was collected either from cattle, dogs, or rabbits and washed twice with sterilized physiological saline $(0.9 \% \mathrm{NaCl})$ by centrifugation at $1,000 \times g$ for $10 \mathrm{~min}$. The resulting erythrocytes were then resuspended in saline to $4 \%(\mathrm{v} / \mathrm{v})$. The peptide P4 was dissolved in saline, and $100 \mu l$ of a twofold serially diluted peptide solution and $100 \mu l$ of an erythrocyte suspension were dispensed into 96-well plates in triplicate and incubated at $37^{\circ} \mathrm{C}$ for $1 \mathrm{hr}$. Following centrifugation at $1,000 \times g$ for $5 \mathrm{~min}$, the supernatants were transferred to new 96-well plates and monitored by measuring the absorbance $(A)$ at $540 \mathrm{~nm}$ for released hemoglobin. Controls for 0 and $100 \%$ hemolysis consisted of cells suspended in saline and in $0.1 \%$ Triton X-100, respectively. Percentage hemolysis (\%) was calculated as follows:

Percentage hemolysis $(\%)=\left[\left(A_{540} \mathrm{~nm}\right.\right.$, peptide $-A_{540 \mathrm{~nm}}$; $\left.0.9 \% \mathrm{NaCl}) /\left(A_{540 \mathrm{~nm}, 0.1 \% \text { TritonX-100 }}-A_{540 \mathrm{~nm} ; 0.9 \% \mathrm{NaCl}}\right)\right] \times 100$.

Cytotoxicity assay: The CellTiter $96^{\circledR}$ Non-Radioactive Cell Proliferation Assay System (Promega) was applied to examine the toxicity of the P4 peptide against Vero cells. After being grown in an Eagle's medium, Vero cells were harvested and resuspended in a fresh medium at a final concentration of $1 \times 10^{5}$ cells $/ \mathrm{m} l$. Fifty microliters of the cell suspension was dispensed into each well of a 96-well microtiter plate containing an equal volume of either the two-fold serially diluted $\mathrm{P} 4$ peptide or only the medium. After an additional $72 \mathrm{hr}$ of incubation, color was developed by adding respective dye solution followed by $4 \mathrm{hr}$ of additional incubation. The reaction was then stopped by adding a solubilization solution, and absorbance was recorded at $550 \mathrm{~nm}$ in a microplate reader (BIO-RAD). Cytotoxicity was expressed as the percentage inhibition of cell growth (\%) and was calculated as follows:

Percentage cell growth inhibition $(\%)=1-\mathrm{B} / \mathrm{A}$, where $\mathrm{A}$ and $\mathrm{B}$ represent the absorbance value in the presence or 
absence of the peptide.

\section{RESULTS}

Chemicophysical characteristics: Antimicrobial peptides are typically relatively short (12 to 100 amino acids), positively charged (net charge of +2 to +9 ), amphiphilic, and hydrophobic, as reviewed by many researchers $[15,18,26$, 36]. Table 1 shows the predicted chemicophysical properties of the longicin sequence (without signal peptide) and its four synthetic analogs. The size of the peptides ranged from 13 to 52 amino acids. All the synthetic analogs (except P1) and longicin were positively charged, ranging from +3 to +5 , and had a $\mathrm{pI}$ value higher than 9 . It has been reported that a peptide net charge from +3 to +5 results in increasing antibacterial activity, whereas a net charge from +6 to +7 leads to increased hemolytic propensity and loss of antimicrobial activity [4].

Hydrophobicity is an essential feature for antimicrobial peptide membrane interaction. However, increase of the hydrophobicity levels is strongly correlated with mammalian cell toxicity and loss of antimicrobial specificity. The GRAVY index, which indicates peptide hydrophobicity, was higher (but at moderate level) in P4 than those of longicin and other partial peptides. The aliphatic indice were found to be almost the same in all peptides, suggesting no differences in heat stability.

Pathak et al. [24] suggested that amphipathicity is more important than hydrophobicity and $\alpha$-helical content in governing antimicrobial peptide activity. When the average amphipathicity of each peptide was estimated using the software WHAT, the peptide was assumed to adopt either an $\alpha$ helical or a $\beta$-sheet conformation, as shown in Table 1.
Regarding the $\alpha$-helix, P2 and P4 were highly amphipathic, whereas P3 and longicin were moderately amphipathic, and P1 was less so (Table 1). Similar results were found when the peptides were analyzed by the software Antheprot 2000 V 6.0; they are presented as a helical wheel in Fig. 1. On the other hand, regarding the $\beta$-sheet, $\mathrm{P} 2$ was also found to be highly amphipathic, although P3 and P4 were slightly amphipathic, and $\mathrm{P} 1$ and longicin were moderately so (Table 1). It is also noteworthy that longicin had four negatively charged acidic residues, and all of them were located at the N-terminal representing the $\mathrm{P} 1$ peptide (Table 1). The only active partial peptide (P4) was located at the C-terminal of longicin.

Secondary structure prediction: It is generally agreed that the structure of a protein is more highly conserved than its sequence. Therefore, we attempted to predict the secondary structure using the Hierarchical Neural Network (HNN), as shown in Fig. 2. The figure shows that longicin is characterized by a $\beta$-strand and a short $\alpha$-helix. The P4 peptide represents the well-developed $\beta$-strand part, and $\mathrm{P} 3$ represents the helix part. The $\mathrm{P} 1$ is composed of a short $\beta$-strand with a random coil, whereas $\mathrm{P} 2$ is fully composed of a random coil. As shown in Table 1, longicin is rich in cysteine residues (6 cysteines), three of which were distributed in P4, two in P3, and one in P2. It is believed that disulphide bonds are involved in stabilizing the peptide structure and may play a role in the antimicrobial activity [36]. With the bioinformatics tool DIpro, the disulphide bonds were predicted in the peptides. DIpro classified only longicin having 3 disulfide bonds between cysteine positions, 18-39, 25-47 and 29-49; however, the probability of forming a single disulphide bond in P3 (between Cys5-10) and P4 (between Cys9-17) was also suggested.
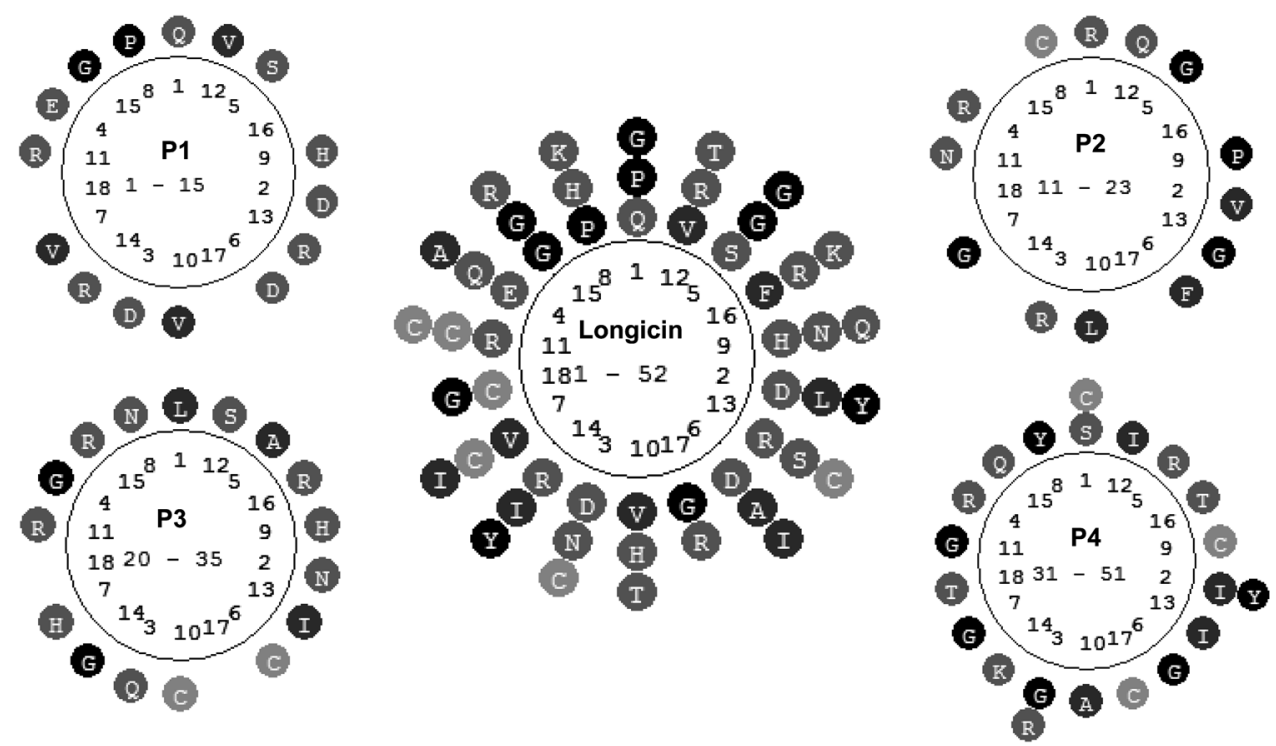

Hydrophilic Hydrophobic Others

Fig. 1. Helical wheel projection of longicin and its four synthetic analogs. The red circles are hydrophilic amino acids, and the blue circles, hydrophobic ones. The green circles indicate cysteine residues. 


$\begin{array}{ccccc}10 & 20 & 30 & 40 & 50 \\ 1 & 1 & 1 & 1 & 1 \\ \text { QDDESDVPHVRVRRGFGCPLNQGACHNHCRS IGRRGGYCAGI IKQTCTCYRK } & \text { Amino acid sequence }\end{array}$

Longicin: cccccccceeeecccccccccccccchhhhcccccceeeeeecccccc

P-1: $\operatorname{ccccccccceeeccc}$
P-2:
P-3:
P-4:

Predicted secondary structure, where c: random coil, e: extended strand, and h: alpha helix

Fig. 2. The secondary structures of longicin (without signal peptide) and its four synthetic analogues were predicted using a Hierarchical Neural Network (HNN).

(A)

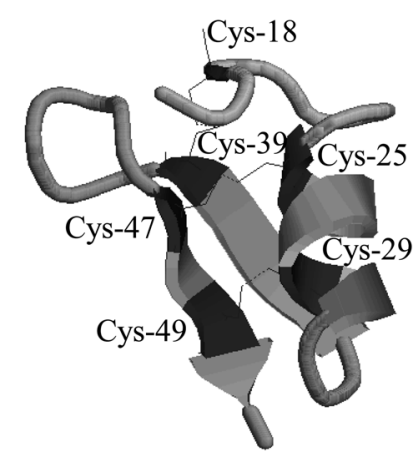

(B)

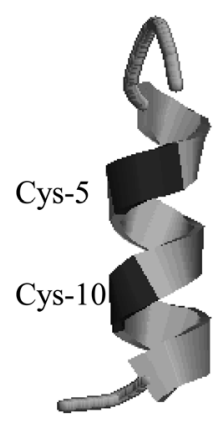

(C)

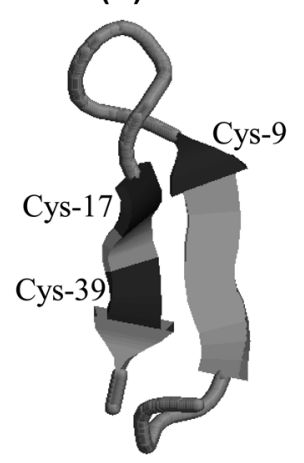

Fig. 3 Modeled tertiary structure of longicin (A) and its two analogs, P3 (B) and P4 (C), based on the template $1 \mathrm{fjn} . p d b$ (an arthropod defensin). The position of the cysteine residues is indicated in blue.

Modeled tertiary structure: The longicin sequence (without the signal peptide) was submitted to the Swiss-Model Protein Modeling Server (http://swissmodel.expasy.org/ SWISS-MODEL.html) for automated modeling via the "first approach mode". The server generated a three-dimensional model of longicin based on the template from the Mediterranean muscle defensin (1fjnA.pdb) [34]. The modeled longicin was composed of residues ranging from 15 to 51 and had a $63.2 \%$ sequence identity with the template molecule. The partial peptides P3 and P4 were also separately modeled based on the same template using a SwissModel alignment mode. The modeled molecules were further processed by RasMol and are shown in Fig. 3. However, P1 and P2 could not be modeled.

Based on the structure, antimicrobial peptides are classified into four major classes: $\beta$-sheet, $\alpha$-helical, loop and extended $[15,26]$. The predicted secondary structure (Fig. 2) and modeled tertiary structure (Fig. 3) suggested longicin as a mixed-structure defensin class peptide (Fig. 3A), whereas $\mathrm{P} 3$ is suggested to be a helical peptide (Fig. 3B) and P4, a $\beta$-sheet peptide (Fig. 3C). These predicted structures indicated that the antimicrobial activity of $\mathrm{P} 4$ could be due to the well-developed $\beta$-sheet. The modeled structure also showed that longicin has 3 disulphide bonds (blue line) cor- responding to the predicted results by DIpro, whereas P3 and $\mathrm{P} 4$ have no disulphide bond.

Electrostatic potential: According to the molecular electroporation theory, the electrostatic potential on the molecular surface plays an important role for the electrostatic bonding between the antimicrobial peptides and the negatively charged bacterial cell membrane [10]. With the software Arguslab 4.01, we generated a brokenheaven pdb file that was then loaded onto software CCP4MG to compute the electrostatic potential, as shown in Fig. 4. Red color is used to indicate 0.5 below the normal range, whereas blue color indicates 0.5 above the normal range. The electrostatic potential of the $\mathrm{P} 4$ peptide was obviously superior to that of P1 and also slightly higher than that of longicin because of the acidic amino acid residues located on the P1 peptide, which produced an electrostatic potential below the normal range, as indicated by red color. The peptides P2 and $\mathrm{P} 3$ also showed an electrostatic potential almost identical to that of P4. Although longicin had a greater net positive charge $(+5)$ than $\mathrm{P} 4(+4)$, the presence of a negatively charged P1 (-1) domain was probably due to the lower electrostatic potential as well as slightly lower activity than that of $\mathrm{P} 4$, as reported by Tsuji et al. [33].

CD Spectroscopy analysis: Many peptides are reported to 

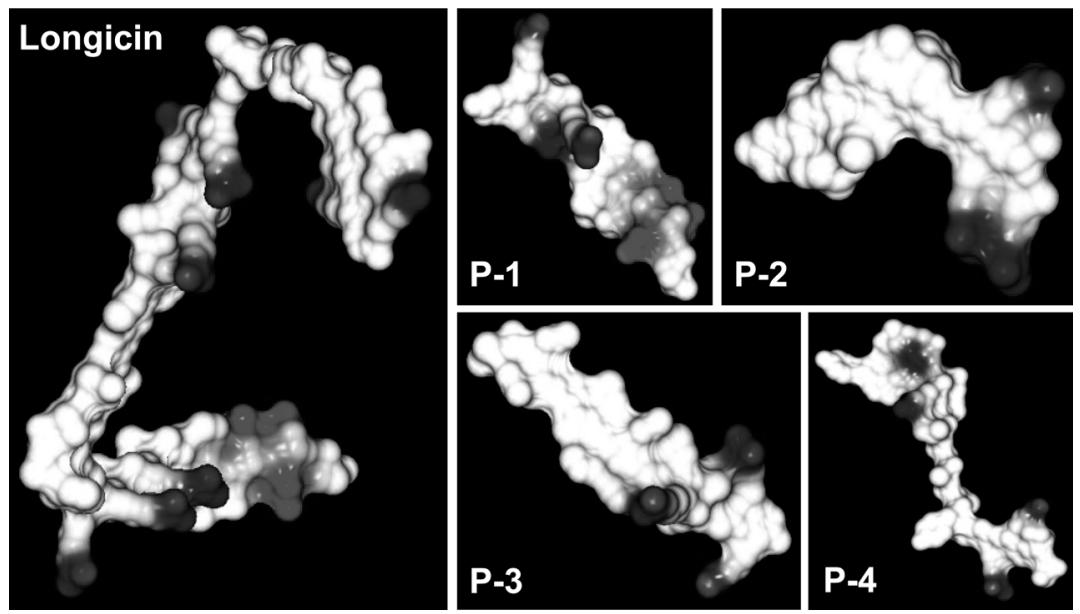

Fig. 4. Electrostatic potential of longicin and its four synthetic analogs. Red and blue indicate 0.5 below and 0.5 above the normal range of the electrostatic potential, respectively.

(A)
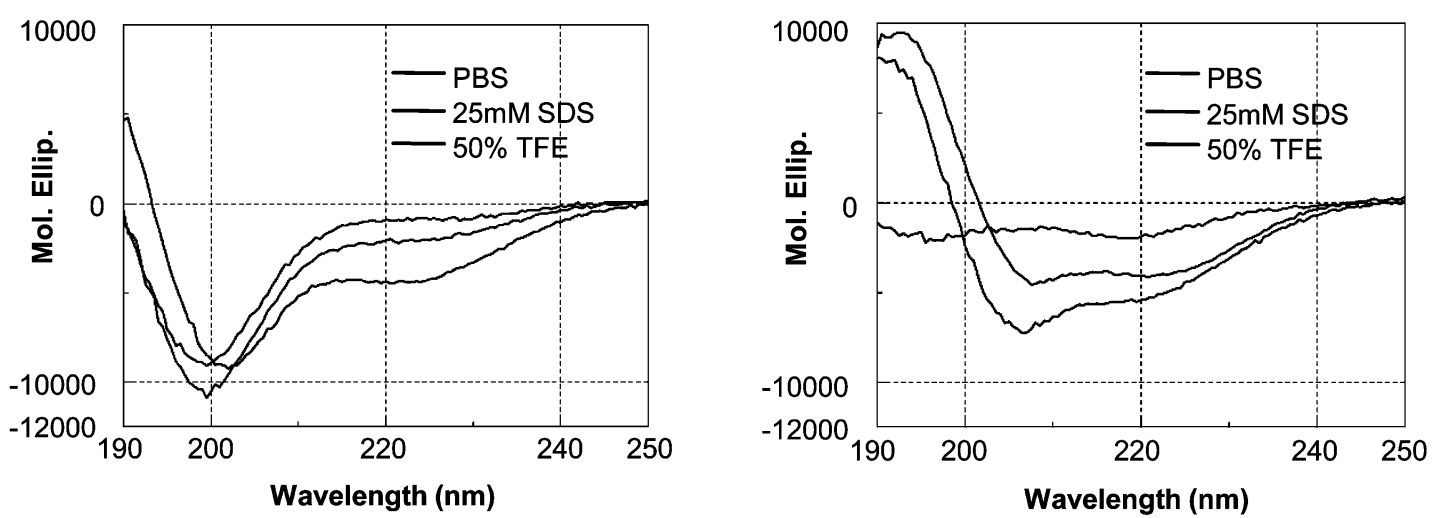

(C)

\begin{tabular}{llrccc}
\hline Peptide & Solvent & $\begin{array}{c}\alpha \text {-helix } \\
(\%)\end{array}$ & $\begin{array}{c}\beta \text {-sheet } \\
(\%)\end{array}$ & $\begin{array}{c}\beta \text {-turn } \\
(\%)\end{array}$ & $\begin{array}{c}\text { Random } \\
\text { coil (\%) }\end{array}$ \\
\hline \multirow{4}{*}{ P1 } & $\mathrm{dH}_{2} \mathrm{O}$ & 5.7 & 26.3 & 0.0 & 68.0 \\
& $\mathrm{TFE} / \mathrm{dH}_{2} \mathrm{O}$ & 13.1 & 21.3 & 0.0 & 65.6 \\
& $\mathrm{SDS} / \mathrm{dH}_{2} \mathrm{O}$ & 13.2 & 18.1 & 0.0 & 68.7 \\
\cline { 2 - 6 } $\mathrm{P} 4$ & $\mathrm{dH}_{2} \mathrm{O}$ & 0.0 & 37.1 & 0.0 & 72.9 \\
& $\mathrm{TFE} / \mathrm{dH}_{2} \mathrm{O}$ & 26.6 & 26.6 & 0.0 & 46.3 \\
& $\mathrm{SDS} / \mathrm{dH}_{2} \mathrm{O}$ & 39.7 & 34.8 & 4.7 & 20.9 \\
\hline
\end{tabular}

Fig. 5. CD Spectra of P1 (A) and P4 (B) in the presence or absence of membrane-mimic conditions. The content of secondary structural elements is shown in tabular form $(\mathrm{C})$.

exist in relatively unstructured or extended conformations prior to interaction with bacterial membranes [15]. Therefore, the secondary structure of $\mathrm{P} 1$ and $\mathrm{P} 4$ peptides in aqueous solution or in the presence of membrane-mimicking conditions were observed by performing CD spectroscopy. The membrane-mimicking condition was provided using structure-promoting agents, such as TFE or SDS. Peptides were dissolved in Mili-Q water containing 50\% TFE or 25 $\mathrm{mM}$ SDS or in Mili-Q water only at a concentration of 0.2 $\mathrm{mg} / \mathrm{ml}$. As shown in Fig. 5, both peptides had almost an identical $\beta$-sheet content with a very low helical content and a high random coil content in the aqueous solution. However, no significant changes in the secondary structure of the peptide P1 were observed in the presence of structure-promoting agents. Conversely, P4 was largely unstructured in the aqueous solution, and no $\alpha$-helix content was observed (Figs. 5B and 5C); however, the peptide underwent a significant transition to a typical $\alpha$-helical conformation follow- 
Table 2. Searching for sequence similarity of the peptide P4 against ticks and other organisms

\begin{tabular}{|c|c|c|c|c|}
\hline Organism Source & Sequence & & $\begin{array}{c}\text { Identity } \\
(\%)\end{array}$ & $\begin{array}{c}\text { Similarity } \\
(\%)\end{array}$ \\
\hline Synthetic peptide (P-4) & SIGRRGGYCAGIIKQTCTCYR & 21 & & \\
\hline \multicolumn{5}{|l|}{ Ticks } \\
\hline$\overline{\text { Haemaphysalis longicornis }}$ & QDDESDVPHVRVRRGFGCPLNQGACHNHCRSIGRRGGYCAGIIKQTCTCYRK & 74 & 100 & 100 \\
\hline Ixodes scapularis $(S G)$ & QEEENQVAHVRVRRGFGCPFDQGACHRHCQSIGRRGGYCAGFIKQTCTCYHN & 74 & 95 & 100 \\
\hline I. scapularis & QEEENQVAHVRVRRGFGCPFDQGACHRHCQSIGRRGGYCAGFIKQTCTCYHN & 74 & 95 & 100 \\
\hline Rhipicephalus (Boophilus) microplus & VPAESEMAHLRVRRGFGCPFNQGACHRHCRSIRRRGGYCAGLIKQTCTCYRN & 74 & 90.48 & 95.24 \\
\hline Dermacentor variabilis & APAESEVAHLRVRRGFGCPLNQGACHNHCRSIRRRGGYCSGIIKQTCTCYRN & 74 & 90.48 & 95.24 \\
\hline D. andersoni & APAESEVAHLRVRRGFGCPLNQGACHNHCRSIRRRGGYCSGIIKQTCTCYRN & 74 & 90.48 & 95.24 \\
\hline Argas monolakensis & DDGDDDAALTRVRRGFGCPFNQGACHRHCQSIGRKGGYCSGLFKQTCTCYRH & & 80.95 & 100 \\
\hline \multicolumn{5}{|l|}{$\underline{\text { Scorpion }}$} \\
\hline Sahara scorpion & GFGCPFNQGACHRHCRSIRRRGGYCAGLFKQTCTCYR & 37 & 85.71 & 95.24 \\
\hline Yellow scorpion & GFGCPLNQGACHRHCRSIRRRGGYCAGFFKQTCTCYRN & 38 & 85.71 & 95.24 \\
\hline \multicolumn{5}{|l|}{ Mussel } \\
\hline Eastern oyster & GFGCPWNRYQCHSHCRSIGRLGGYCAGSLRLTCTCYRS & 38 & 76.19 & 85.71 \\
\hline
\end{tabular}

ing the addition of SDS (39.7\%), and a moderate transition was observed by the addition of TFE $(26.6 \%)$. With the increase of the helical content, a concomitant reduction of the random coiled structure was observed in the presence of TFE or SDS. However, a drastic reduction of the random coil was found in the presence of SDS, whereas the presence of TFE showed a moderate influence (Fig. 5C). The $\beta$-sheet structure was constant in the presence of TFE but increased slightly with the addition of SDS, as shown in Fig. 5C. In the presence of SDS, $\mathrm{P} 4$ also showed a low $\beta$-turn content (Fig. 5C). The $\beta$-sheet peptide tachyplesin I was also reported to have a type I turn that connects an antiparallel $\beta$ sheet [26].

Sequence homology of P4: We searched the sequence similarity of the $\mathrm{P} 4$ peptide from protein databases using the program FASTA and SSEARCH. The alignment result presented in Table 2 showed that the molecules identified in other ticks and organisms have the $\mathrm{P} 4$ analogous domain at the C-terminal.

Cytolytic activity of the P4 peptide: The peptide $\mathrm{P} 4$ was challenged against red blood cells of different species for hemolytic activity and also against Vero cells for cytotoxicity in order to evaluate the safety/toxicity of the peptide. The result presented in Fig. 6A showed that the $\mathrm{P} 4$ peptide had a very low hemolytic activity against erythrocytes of all three species even at high concentrations. The highest hemolysis percentage (less than $15 \%$ ) was estimated against bovine erythrocytes at a concentration of $500 \mu \mathrm{M}$. On the other hand, although the maximum inhibition rate of Vero cell growth was estimated to be less than 50\% (Fig. 6B), significant growth inhibition started to occur at a concentration of $16 \mu \mathrm{M}$.

\section{DISCUSSION}

Structural comparison of longicin and its synthetic analogs: Structural parameters, such as the conformation, charge, hydrophobicity, hydrophobic moment, amphipathicity, and polar angle of peptides, are considered to be rele-
(A)

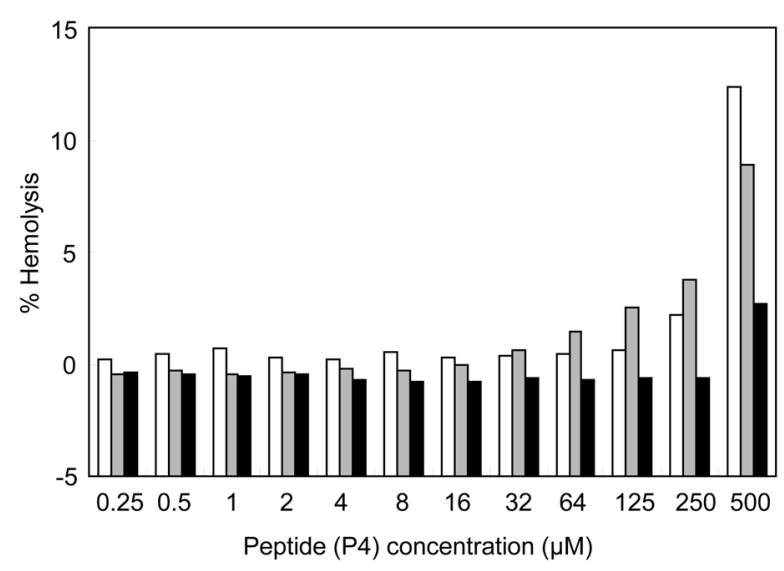

(B)

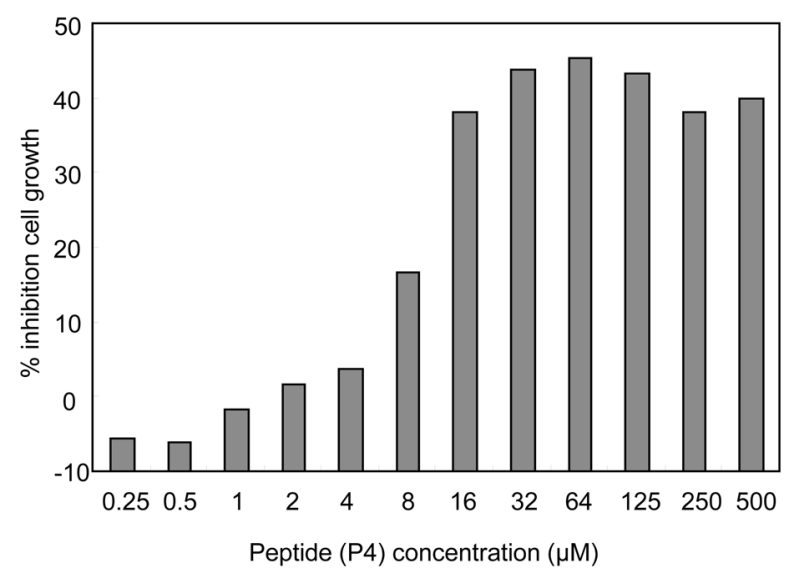

Fig. 6. Hemolytic activity of P4 against erythrocytes of cattle, dog, or rabbit (A) and cytotoxicity of P4 against Vero cells (B). Values are representative of two separate experiments in triplicate. The standard error mean was less than $10 \%$. 
vant to antimicrobial activity [36]. Therefore, some of these molecular determinants of longicin and its synthetic analogs was predicted using various bioinformatic tools and were compared to find out the characteristics which are responsible for $\mathrm{P} 4$ as an active antimicrobial domain in the present examination. The positive charge on the peptide is believed to be important for the initial electrostatic attraction of antimicrobial peptides to negatively charged phospholipid membranes of bacteria and other microorganisms [15]. Although the predicted secondary structure of P1 (Fig. 2) indicated a short $\beta$-sheet region with a random coil, according to the chemicophysical characteristics, P1 was found to be negatively charged, less hydrophobic, and less amphipathic (Table 1). A low electrostatic potential (Fig. 4) and a poor relationship between hydrophobicity and amphipathicity, as projected in the helical wheel diagram (Fig. 1), were also observed. These features could be responsible for the inactivity of P1. As shown in Table 1, P2 was positively charged with a high $\mathrm{pI}$ value and an electrostatic potential almost identical to that of P4 (Fig. 4). In addition, P2 had a GRAVY index almost identical to that of longicin as well as high amphipathicity either as an $\alpha$-helix or a $\beta$-sheet (Table 1). The peptide also had a good relationship between amphipathicity and hydrophobicity, as projected in the helical wheel (Fig. 1). Despite these structural features, the reasons for the inactivity of $\mathrm{P} 2$ could be attributed to the lack of a secondary structure. As shown in Fig. 2, the P2 contained a random coil and only one cysteine residue. On the other hand, the predicted secondary structure (Fig. 2) and modeled three-dimensional structure (Fig. 3) indicated that the peptide P3 had a short helical region and the possibility of forming a disulphide bond due to the presence of two cysteine residues. The $\alpha$-helix is an important conformation of antimicrobial peptides. Magainins and cecropins are examples of an $\alpha$-helical peptide with an amphiphilic region [21]. However, although P3 had a positive charge with a high pI value, good amphipathicity as an $\alpha$-helix and a good electrostatic potential, the peptide was less hydrophobic (Table 1 ), as was also projected in the respective helical wheel diagram (Fig. 1).

Structural analysis of the P4 peptide: From the findings described above, it appears that the peptide $\mathrm{P} 4$ has the following characteristics: optimum charge, moderate hydrophobicity, amphipathicity, good electrostatic potential, the possibility of forming a disulphide bond, and a well-developed beta sheet. Therefore, we further analyzed the peptide $\mathrm{P} 4$ by $\mathrm{CD}$ spectroscopy. In the aqueous environment, CD spectroscopy results corresponded to the predicted secondary structure, as shown in Fig. 2. However, the helical transition of $\mathrm{P} 4$ under membrane-mimetic conditions suggested that both the $\beta$-sheet and $\alpha$-helix could be involved with the antimicrobial mechanism of P4. Therefore, it could be assumed that like the larger $\beta$-sheet family peptides, $\mathrm{P} 4$ also contains minor helical segments. Until now, many molecules have been identified in different ticks. In our previous study [33], P4 is indicated as an active motif of longicin. The sequence homology search displayed in Table 2, sug- gesting P4 as a conserved antimicrobial domain.

The hemolytic activity and cytotoxicity of antimicrobial peptides are very important factors for evaluating their safety/toxicity. Various parameters, such as the hydrophobicity $[14,22,28]$, cationicity $[4,30]$, number of disulphide bridges, and length of the peptides [12], are related with the cytolytic activity of antimicrobial peptides. Our previous study showed that $\mathrm{P} 4$ can kill bacteria at a concentration ranging from $2-10 \mu \mathrm{M}$ [33]. Therefore, the $\mathrm{P} 4$ peptide could be developed as a future therapeutic agent against bacteria.

ACKNOWLEDGMENT(S). This study was supported by the Bio-oriented Technology Research Advancement Institution (BRAIN), Grants-in-Aid for Scientific Research (A) from the Japan Society for the Promotion of Science (JSPS), and a grant from the 21 st Century COE Program (A-1), Ministry of Education, Sports, Science and Technology of Japan.

\section{REFERENCES}

1. Ahmad, I., Perkins, W. R., Lupan, D. M., Selsted, M. E. and Janoff, S. A. 1995. Liposomal entrapment of the neutrophilderived peptide indolicidin endows it with in vivo antifungal activity. Biochim. Biophys. Acta 1237: 109-114.

2. Beier, J. C. 1998. Malaria parasite development in mosquitoes. Annu. Rev. Entomol. 43: 519-543.

3. Ceraul, S. M., Dreher-Lesnick, S. M., Gillespie, J. J., Rahman, M. S. and Azad, A. F. 2007. New tick defensin isoform and antimicrobial gene expression in response to Rickettsia monatanensis challenge. Infect. Immun. 75: 1973-1983.

4. Dathe, M., Nikolenko, H., Meyer, J., Beyermann, M. and Bienert, M. 2001. Optimization of the antimicrobial activity of magainin peptides by modification of charge. FEBS Lett. 501: 146-150.

5. Dimopoulos, G., Muller, H. M., Levashina, E. A. and Kafatos, F. C. 2001. Innate immune defense against malaria infection in the mosquito. Curr. Opin. Immunol. 13: 79-88.

6. Fogaca, A. C., da Sliva, P. I., Miranda, M. T., Bianchi, A. G., Miranda, A., Ribolla, P. E. and Daffre, S. 1999. Antimicrobial activity of a bovine hemoglobin fragment in the tick Boophilus microplus. J. Biol. Chem. 274: 25330-25334.

7. Fogaca, A. C., Lorenzini, D. M., Kaku, L. M., Esteves, E., Bulet, P. and Daffre, S. 2004. Cysteine-rich antimicrobial peptides of the cattle tick Boophilus microplus: isolation, structural characterization and tissue expression profile. Dev. Comp. Immunol. 28: 191-200.

8. Gura, T. 2001. Innate immunity. Ancient system gets new respect. Science 291: 2068-2071.

9. Hancock, R. E. W. and Patrzykat, A. 2002 Clinical development of cationic antimicrobial peptides: from natural to novel antibiotics. Curr. Drug Targets Infect. Disord. 2: 79-83.

10. Hao, G., Shi, Y. H., Han, J. H., Li, Q. H., Tang, Y. L. and Le, G. W. 2007. Design and analysis of structure-activity relationship of novel antimicrobial peptides derived from the conserved sequence of cecropin. J. Peptide Sci. 14: 290-298.

11. Hoffmann, J. A. 1997. Immune responsiveness in vector insects. Proc. Natl. Acad. Sci. U.S.A. 94: 11152-11153.

12. Hwang, P. M. and Vogel, H. J. 1998. Structure function relationships of antimicrobial peptides. Biochem. Cell Biol. 76: 
$235-246$

13. Hynes, W. L., Ceraul, S. M., Todd, S. M., Seguin, K. C. and Sonenshine, D. E. 2005. A defensin-like gene expressed in the black-legged tick, Ixodes scapularis. Med. Vet. Entomol. 19: 339-344.

14. Javadpour, M. M. and Barkley, M. D. 1997. Self-assembly of designed antimicrobial activity peptides in solution and micelles. Biochemistry 36: 9540-9549.

15. Jenssen, H., Hamill, P. and Hancock, R. E. W. 2006. Peptide antimicrobial agents. Clin. Microbiol. Rev. 19: 491-511.

16. Johanson, J., Gudmundsson, G. H., Rottenberg, M., Berndt, K. D. and Agerbeth, B. 1998. Conformation-dependent antibacterial activity of the naturally occurring human peptide LL-37. J. Biol. Chem. 273: 3718-3724.

17. Johns, R., Sonenshie, D. E. and Hynes, W. L. 2001. Identification of a defensin from the hemolymph of the American dog tick Dermacentor variabilis. Insect Biochem. Mol. Biol. 31: 857-865.

18. Kamysz, W., Okroj, M. and Lukasiak, J. 2003. Novel properties of antimicrobial peptides. Acta Biochim. Polo. 5: 461-469.

19. Lai, R., Lomas, L. O., Jonczy, J., Turner, P. C. and Rees, H. H. 2004. Two novel non-cationic defensin-like antimicrobial peptides from haemolymph of the female tick, Amblyomma hebraeum. Biochem. J. 379: 681-685.

20. Lee, D. G., Kim, H. N., Park, Y., Kim, H. K., Choi, C. H. and Hahm, K. S. 2002. Design of novel analogue peptides with potent antibiotic activity based on the antimicrobial peptide, HP (2-20) derived from N-terminus of Helicobacter pylori ribosomal protein L1. Biochim. Biophys. Acta 1598: 185-194.

21. Lehrer, R. I. and Ganz, T. 1999. Antimicrobial peptides in mammalian and insect host defence. Curr. Opin. Immunol. 11: 23-27.

22. Matsuzaki, K., Yoneyama, S., Fujii, N., Miyajima, K., Yamada, K., Kirino, Y. and Anzali, K. 1997. Membrane permeabilization mechanisms of cyclic antimicrobial peptide, tachyplesin 1 and its linear analog. Biochemistry 36: 97999806.

23. Nakajima, Y., van der Goes van Naters-Yasui, A., Taylor, D. and Yamakawa, M. 2002. Antibacterial peptide defensin is involved in midgut immunity of the soft tick, Ornithodoros moubata. Insect Mol. Biol. 11: 611-618.

24. Pathak, N., Salas-Auvert, R., Ruche, G., Janna, M. H., McCarthy, D. and Harrison, R. G. 1995. Comparison of the effects of hydrophobicity, amphipathicity, and alpha-helicity on the activities of antimicrobial peptides. Proteins 22: 182-186.

25. Potterton, L., McNicholas, S., Krissinel, E., Gruber, J., Cowtan, K., Emsley, P., Murshudov, G. N., Cohen, S., Perrakis, A. and Noble, M. 2004. Developments in the CCP4 molecular-graphics project. Acta Crystallogr. D. 60: 22882294.

26. Powers, J. P. and Hancock, R. E. W. 2003. The relationship between peptide structure and antibacterial activity. Peptides 24: 1681-1691.
27. Rudenko, N., Golovchenko, M., Edwards, M. J. and Grubhoffer, L. 2005. Differential expression of Ixodes ricinus tick genes induced by blood feeding or Borrelia burgdorferi infection. J. Med. Entomol. 42: 36-41.

28. Saberwal, G. and Nagaraj, R. 1994. Cell-lytic and antibacterial peptides that act by perturbing the barrier function of membranes: facets of their conformational features, structure-function co-relations, and membrane perturbing abilities. Biochem. Biophys. Acta 1197: 109-131.

29. Skerlavaj, B., Benincasa, M., Risso, A., Zanetti, M. and Gennaro, R. 1999. SMAP-29, a potent antibacterial and antifungal peptide from sheep leukocytes. FEBS Lett. 463: 58-62.

30. Skerlavaj, B., Gennaro, R., Bagella, L., Merluzzi, L., Risso, A. and Zanetti, M. 1996. Biological characterization of two novel cathelicidin-derived peptides and identification of structural requirements for their antimicrobial and cell lytic activities. $J$. Biol. Chem. 271: 28375-28381.

31. Stark, M., Liu, L. P. and Deber, C. M. 2002. Cationic hydrophobic peptides with antimicrobial activity. Antimirob. Agents Chemother. 46: 3585-3590.

32. Subbalakshmi, C., Nagaraj, R. and Sitaram, N. 1999. Biological activities of C-terminal 15-residue synthetic fragment of melittin: design of an analog with improved antibacterial activity. FEBS Lett. 448: 62-66.

33. Tsuji, N., Battsetseg, B., Boldbaatar, D., Miyoshi, T., Xuan, X., Oliver, J. H. and Fujisaki, K. 2007. Babesial vector tick defensin against Babesia sp. parasites. Infect. Immun. 75: 3633-3640.

34. Yang, Y. S., Mitta, G., Chavanieu, A., Calas, B., Sanchez, J. F., Roch, P. and Aumelas, A. 2000. Solution structure and activity of the synthetic four-disulfide bond Mediterranean mussel defensin (MGD-1). Biochemistry 39: 14436-14447.

35. Yang, S. T., Shin, S. Y., Hahmb, K. S. and Kim, J. I. 2006. Design of perfectly symmetric Trp-rich peptides with potent and broad-spectrum antimicrobial activities. Int. J. Antimicrob. Agents 27: 325-330.

36. Yeaman, M. R. and Yount, N. Y. 2003. Mechanism of antimicrobial peptide action and resistance. Pharmacol. Rev. 55: 27 55 .

37. Zanetti, M., Gennaro, R., Skerlavaj, B., Tomasinsig, L. and Circo, R. 2002. Cathelicidin peptides as candidates for a novel class of antimicrobials. Curr. Pharm. Dis. 8: 779-793.

38. Zasloff, M. 2002. Antimicrobial peptides of multicellular organisms. Nature 415: 389-395.

39. Zhai, Y. and Saier, M. H. Jr. 2001. A web-based program (WHAT) for the simultaneous prediction of hydropathy, amphipathicity, secondary structure and transmembrane topology for a single protein sequence. J. Mol. Microbiol. Biotechnol. 3: 501-502.

40. Zhou, J., Liao, M., Ueda, M., Gong, H., Xuan, X. and Fujisaki, K. 2007. Sequence characterization and expression patterns of two defensin-like antimicrobial peptides from the tick Haemaphysalis longicornis. Peptides 28: 1304-1310. 